\title{
Low back pain as the presenting sign in a patient with primary extradural melanoma of the thoracic spine - A metastatic disease 17 Years after complete surgical resection
}

\author{
Darko Katalinic ${ }^{1 *}$, Branimir Anic ${ }^{2}$, Ranka Stern-Padovan ${ }^{3}$, Miroslav Mayer $^{2}$, Mirna Sentic $^{2}$, Nada Cikes², \\ Kamelija Zarkovic ${ }^{4}$, Snjezana Dotlic ${ }^{4}$ and Stjepko Plestina ${ }^{1}$
}

\begin{abstract}
Primary spinal melanomas are extremely rare lesions. In 1906, Hirschberg reported the first primary spinal melanoma, and since then only 40 new cases have been reported. A 47-year-old man was admitted suffering from low back pain, fatigue and loss of body weight persisting for three months. He had a 17-year-old history of an operated primary spinal melanoma from T7-T9, which had remained stable for these 17 years. Routine laboratory findings and clinical symptoms aroused suspicion of a metastatic disease. Multislice computed tomography and magnetic resonance imaging revealed stage-IV melanoma with thoracic, abdominal and skeletal metastases without the recurrence of the primary process. Transiliac crest core bone biopsy confirmed the diagnosis of metastatic melanoma. It is important to know that in all cases of back ore skeletal pain and unexplained weight loss, malignancy must always be considered in the differential diagnosis, especially in the subjects with a positive medical history. Patients who have back, skeletal, or joint pain that is unresponsive to a few weeks of conservative treatment or have known risk factors with or without serious etiology, are candidates for imaging studies. The present case demonstrates that complete surgical resection alone may result in a favourable outcome, but regular medical follow-up for an extended period, with the purpose of an early detection of a metastatic disease, is highly recommended.
\end{abstract}

Keywords: primary spinal melanoma, metastatic disease, low back pain

\section{Background}

Malignant melanoma is an aggressive tumour with a variable prognosis: that depends on tumour site and the extent of surgical resection. According to epidemiological data, its annual incidence has increased significantly in recent years [1]. Primary melanoma of the central nervous system (CNS) is rare and accounts for approximately $1 \%$ of all cases of melanoma [2]. They are either intradural, extradural or have both intra and extradural components. However, primary spinal extradural melanoma is extremely rare [3]. It is a solitary lesion associated with leptomeninges and neural crest, the tissue

\footnotetext{
* Correspondence: darko.katalinic@kbc-zagreb.hr

'Department of Oncology, University Hospital Centre (KBC Zagreb),

University of Zagreb School of Medicine, Zagreb, Croatia

Full list of author information is available at the end of the article
}

source of its precursory melanocytes. In 1906, Hirschberg reported the first primary spinal melanoma, and since then only 40 new cases have been reported [4]. We present a case of primary thoracic extradural spinal melanoma occurring with low back pain and metastatic disease 17 years after the initial surgical resection.

\section{Case presentation}

In 1993, a 30-year-old man without accompanying comorbidity, was hospitalized for a sudden bilateral spastic paraparesis. General physical examination revealed progressive bilateral lower extremity weakness associated with hypoesthesia distal of the dermatome level of T9. A plain myelography showed epidural block of contrast flowing along the spinal canal from the level of T7. Therefore, laminectomy was performed at the 
T7-T9 level which revealed a dark, pigmented, extradurally located tumour measuring $2.5 \times 1 \mathrm{~cm}$., without infiltration of dura and spreading through vertebral foramina. Histopathologic and immunohistochemical analysis confirmed a malignant melanoma (Figure 1A and 1B). The patient did not receive any radiotherapy because surgical resection appeared completely without opening the dura. The patient was also subjected to further clinical and oncological evaluation which did not reveal any other melanoma lesions or metastases and other primary process could not be established. With these data and according to Hayward's criteria [5], the diagnosis of primary spinal melanoma was established. He was discharged from the hospital in a good general condition with the recommendation for a regular follow-up and he was cleared disease-free a few years after the operation without any need for specific oncological treatment.

In 2010, 17 years later, the same patient was admitted to our rheumatology department with a three-month history of low back pain, fatigue and loss of body weight. He was treated with medication and physiotherapy, but his symptoms did not subside. Physical examination showed a right sacroiliac joint tenderness on palpation with a positive Mennel's sign, Lasègue's sign

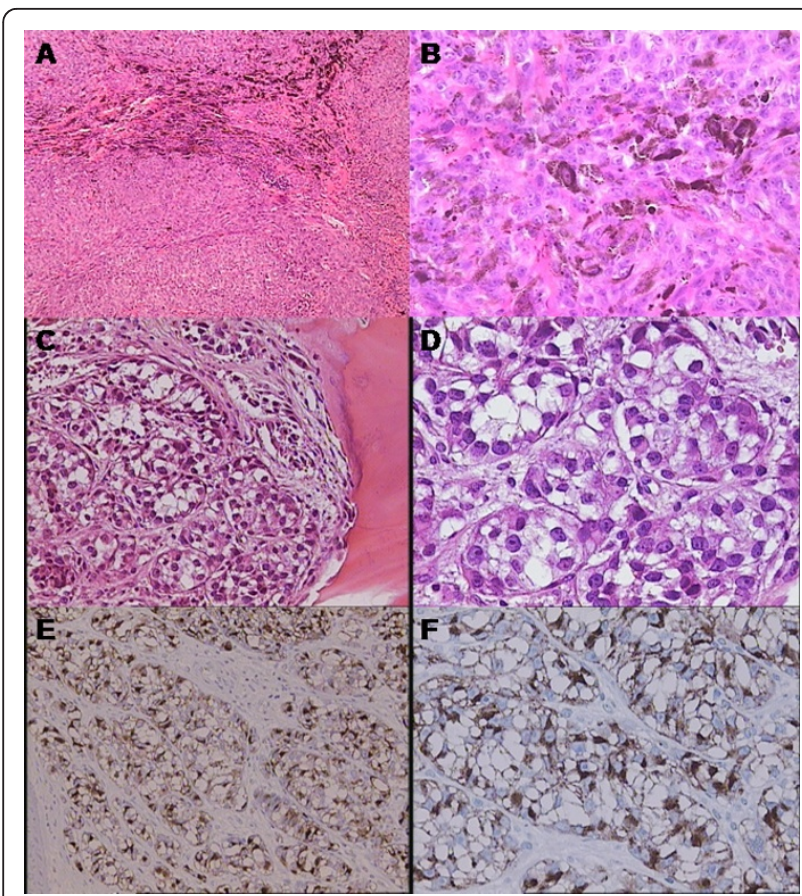

Figure 1 Histopathological evaluation. Hematoxylin and eosin histologic analysis revealed a highly cellular malignant tumour with prominent nucleoli (image A 100x, images B and C 200x, image D 400x). Immunohistochemical study shows that the tumour cells stained diffusely positive for Melan-A and HMB-45, consistent with the diagnosis of melanoma (images E 200x, image F 400x). was bilaterally negative and the lumbar vertebral segment motility was very painful. In this period he had no history of fever or pain in other joints, bones and muscles. He did not notice any skin lesions and he didn't have any other problems other than the above. The stool and urine were normal. General physical examination revealed no signs of lymphadenopathy, splenomegaly, hepatomegaly or other abnormalities. Routine laboratory tests showed anemia (hemoglobin $102 \mathrm{~g} / \mathrm{L}$, range $138-175)$, thrombocytosis $\left(641 \times 10^{9} / \mathrm{L}\right.$, range 158-424), low serum iron concentration $(3 \mu \mathrm{mol} / \mathrm{L}$, range 8-30), high serum ferritin concentration $(790 \mu \mathrm{g} /$ L, range 15-150), high serum lactate-dehydrogenase activity (745 U/L, range 1-241) and high erythrocyte sedimentation rate $(96 \mathrm{~mm} / \mathrm{h}$, range $3-23)$. Further laboratory studies and blood chemistry including serum glucose level, alkaline phosphatase, renal and hepatic parameters, electrolytes, protein electrophoresis, coagulogram, tumour markers, urinanlysis, were all within normal limits. We suspected he had developed a metastatic disease because the patient had a history of primary spinal melanoma. Chest radiography showed a right hilar lymphadenopathy and pulmonary metastatic lesions. Pelvis and thoracolumbosacral plain radiographs revealed multiple metastatic lesions. Tc-99 m bone scintigraphy showed increased osteoblastic activity, which predominantly affected the axial skeleton. (Figure 2). Transiliac crest core bone biopsy showed tumour tissue composed of large melanocytes with prominent nucleoli, which makes up $90 \%$ of all bone marrow cells (Figure $1 \mathrm{C}$ and 1D). Immunohystochemically, tumour cells give a positive reaction to Melan-A and HMB-45 consistent with the diagnosis of metastatic melanoma (Figure $1 \mathrm{E}$ and $1 \mathrm{~F})$. A staging contrast enhanced multislice

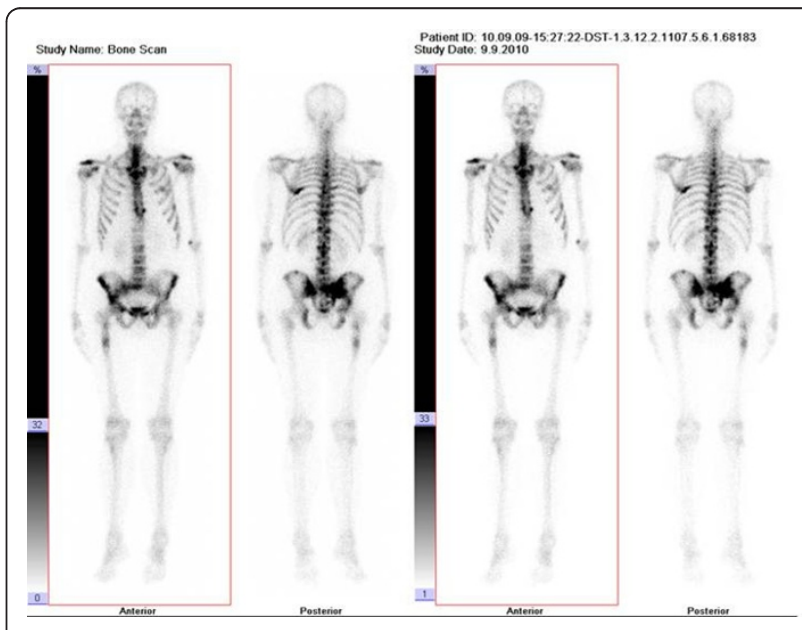

Figure 2 Bone scintigraphy. Bone scintigraphy with Tc-99 m demonstrates extensive osteoblastic activity, predominantly located in the axial skeleton within the spine, pelvis and ribs. 
computed tomography (MSCT) of the chest, abdomen and pelvis revealed stage-IV melanoma with thoracic lymphadenopathy, multiple osteolytic lesions and numerous metastases within lung parenchyma, liver and spleen (Figure 3C-3G). The control magnetic resonance imaging (MRI) of the thoracic spine showed no recurrence of the primary process (Figure $3 \mathrm{~A}$ and $3 \mathrm{~B}$ ). The patient was seen by a medical oncologist with a view to chemotherapy. We have decided to start with Dartmouth regimen (dacarbazine, cisplatin, carmustine, and tamoxifen) which has been reported to induce major tumour responses in $40 \%$ to $50 \%$ of stage-IV melanoma patients [6]. He has received only three cycles of Dartmouth regimen and he tolerated the treatment very well. Unfortunately, during his next hospitalization he died as a result of febrile neutropenia, sepsis and multiple organ failure.

\section{Discussion}

Melanomas could occur in any tissue in which melanocytes can normally be found. Primary spinal melanomas are exceedingly rare malignant tumours whose origin can be illustrated by embriology. In 1859, Virchow showed that primary melanomas of the CNS developed from melanocytes located in the leptomeninges. Melanoblasts, the precursors of melanocytes are belived to be derived from the neural crest during early embrionic development. The presence of melanocytes in neural tissue can be explained by the fact that these melanocytes accompany blood vessels to the leptomeninges and can proliferate in the neural parenchyma [4,7]. They can also be precursors to benign melanocytoma, pigmented schwannoma and pigmented medulloblastoma, which is

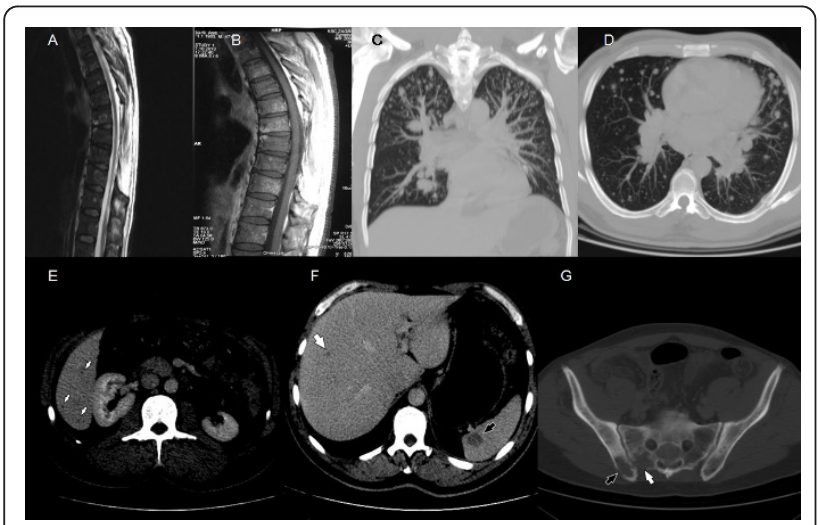

Figure 3 Radiological evaluation. Magnetic resonance sagittal T2 weighted image (image A) and postcontrast sagittal T1 image (image B) of the thoracic spine shows millimetric hyperintense metastases with no residual-recurrent tumor. Multislice computed tomography of the chest and abdomen demonstrated osteolytic (image $\mathrm{G}$ ) and parenchymal metastases (arrows) in lungs (images $\mathrm{C}$ and D), liver and spleen (images $\mathrm{E}$ and $\mathrm{F}$ ). relevant for differential diagnosis [4,8]. A big difficulty when discussing melanoma of the CNS is to decide which cases represent primary growths and which are metastatic disease. In general, melanocytic mass in the CNS is known to be the result of metastasis. Only after detailed clinical work-up including dermatological, ophtalmological and endoscopic examination, a solitary melanotic lesion of the CNS can be identified as a primary tumour. The following criteria should also be considered: no melanoma tumour outside the CNS and involvement of the meninges and/or neural tissue [5]. In all cases of primary spinal melanoma, the clinical presentation suggests progressive spinal cord compression with clinical signs and symptoms of compressive myelopathy. The neurosurgical treatment is the method of choice, but in some cases where surgery is not possible, radiotherapy also may be used. Larson et al. [9] showed an average life expectancy of approximately seven years after surgery with radiotherapy. As opposed to that, the survival time with melanoma of the skin with metastases to CNS was only six months [9]. Considering the wellknown metastazing potential of melanomas, it may seem surprising that primary CNS melanomas do not spread for a long time and may have a favourable outcome after complete neurosurgical excision. Clinically, this is the main reason why distinction between primary and metastatic melanoma is important. In the present case, progression of melanoma was controlled for 17 years, which is an unusually long time. The key factor in this successful, long survival remains unclear. The characteristics of the CNS probably contribute to the nature of this disease and contrary to melanoma of the skin, lymphatic spread would be impossible because there are no lymphatic vessels in the neural tissue. The blood-brain barrier of the neural parenchyma probably also prevents the hematogenous spreading.

At present, MRI has a leading diagnostic role in patients with serious spinal pathology but distinction of tumour type based on MRI findings remains difficult. The MRI findings of melanoma vary deeply depending on the amount of melanin-containing cells and on the presence or absence of hemorrhage $[10,11]$. The paramagnetic effect that derives from the presence of organic radicals from melanin is responsible for hyperintensity on T1 weighted images and hypointensity on T2 weighted images. Although MRI is the primary imaging modality in diagnosis of spinal tumors, histopathologic diagnosis is required to differentiate benign pathologies from malignant disease. Bony metastases of melanoma exhibit a predilection to spread in the axial skeleton with an incidence of 70-86\% [12]. Plain radiography findings of bony metastasis of melanoma are ostelytic lesions, which can not be distinguished from other osteolytic metastases on the basis of imaging criteria. 
Conventional plain radiographs have been reported to identify approximately $40 \%$ of metastatic bone lesions [13]. Radionuclide imaging of bone marrow metastases with a Tc-99 $\mathrm{m}$ is very effective, simple and safe method for the detection of melanoma metastases or recurrent disease [12]. Bone scans remain the study of choice for initial screening, because of their overall sensitivity, lower cost and ability to assess the entire body conveniently [12]. Since computed tomography (CT) facilitates simultaneous examination of multiple sites at risk for metastatic disease and may allow earlier detection of metastatic disease, CT is being used with an increasing frequency for clinical staging of melanoma. It is also being used to monitor clinical response of patients to different therapy [14]. Whole body positron-emission tomography-CT (PET-CT) was found to be capable of uncovering metastases not seen with conventional CT alone and could also be used for initial staging [15]. Thus, the ultimate diagnosis can only be made on the basis of histopathological and immunohystochemical examination.

Melanoma is considered a relatively radioresistant tumour [16]. However, some studies have shown that patients with spinal cord compression may achieve shrinkage of the tumor with radiation therapy $[17,18]$. Radiotherapy is reserved for palliation of symptoms due to local tumour growth [16], as sole decompressive modality or as an adjuvant to laminectomy $[19,20]$. Irradiation regimens should be selected on the basis of patient long-term or short-term prognosis, and on spinal cord tolerance which limits the utilisation of high dose per fraction schedules (30 Gy at 2-3 Gy per day in 15-20 days). In 1995, Hamilton and colleagues [21] first described the use of linear-accelerator-based spinal stereotactic radiosurgery. Most radiosurgical departments currently utilize doses of 12-24 Gy to the margin of the treatment volume and deliver spinal radiosurgery in 1-5 fractions [22,23]. The prescription dose depends in part upon the tumor location and volume as well as the fractionation scheme, surrounding organs at risk, and prior radiotherapy.

Melanoma has also been refractory to most standard systemic therapy for decades. Single-agent or combination chemotherapy drugs in use at this time are of limited value. The two approved treatments, dacarbazine and interleukin-2, have not demonstrated an impact on overall survival. Some novel regimens (multiagent chemotherapy, biochemotherapy, biotherapy with interferon- $\gamma$ and interferon- $\alpha$, antisense bcl-2 oligonucleotide oblimersen, a reactive-oxide species inhibitor or a combined approach) [20-31] have also not significantly impacted overall survival [32]. However, evidence of tumor regression with prolonged time to progression has been seen in patients with melanoma who received cytotoxic $\mathrm{T}$ lymphocyte antibodies (CTLA-4) [33]. Combination of chemotherapy and/or new monoclonal antibody that overcomes CTLA-4mediated $\mathrm{T}$-cell suppression (ipilimumab) improved overall survival [34,35]. Phase 1 and 2 clinical trials of the BRAF kinase inhibitor vemurafenib produced improved rates of overall and progression-free survival in patients with previously untreated melanoma with the BRAF V600E mutation [36]. Our understanding of the biology of melanoma is steadily increasing and there will be a number of new agents in the future which have already entered clinical trials and are promising combined approaches targeting melanoma by different molecular mechanisms.

Finally, early detection of melanoma through patient education regarding clinical characteristics of melanoma, counselling on the risk of developing a metastatic tumor, self-examination and medical examination continues to be of the utmost importance. During melanoma follow-up, patients are clinically monitored in order to detect a relapse. There is currently no scientific consensus on the frequency of follow-up after initial surgical treatment and the use of imaging techniques. Typically patients will be seen every 3-6 months during the first 3 years and every 6-12 months thereafter. Routine laboratory tests, tumor markers (S 100B, tyronsinase), ultrasound of lymph nodes, chest radiography, CT or whole body PET/PET-CT scans may be used in the follow-up of patients with primary melanoma or following treatment of metastases [37,38].

\section{Conclusion}

This case remind us how little we truly know about the biological behavior of melanoma and the patient's inherent biological response to the tumor. It is important to know that in all cases of back ore skeletal pain and unexplained weight loss, malignancy must always be considered in the differential diagnosis, especially in the subjects with a positive medical history. Patients who have back, skeletal, or joint pain that is unresponsive to a few weeks of conservative treatment or have known risk factors with or without serious etiology, are candidates for imaging studies.

Melanomas are unpredictable tumours with a different clinical course. The present case also demonstrates that complete resection alone may result in a favourable outcome, but regular medical follow-up for an extended period, patient education and councelling with the purpose of an early detection of a metastatic disease, is highly recommended.

\section{Consent}

Written informed consent was obtained from the patient for publication of this Case report and any 
accompanying images. A copy of the written consent is available for review by the Editor-in-Chief of this journal.

\author{
Abbreviations \\ CNS: central nervous system; MSCT: multislice computed tomography; MRI: \\ magnetic resonance imaging (MRI); CT: computed tomography; PET-CT: \\ positron-emission tomography; Gy: gray; CTLA-4: cytotoxic T lymphocyte \\ antibodies; BRAF: proto-oncogene BRAF
}

\section{Acknowledgements}

The Authors wish to thank Mr. Kristijan Nikolic and Mr. Marko Cip for technical suggestions in preparation of this manuscript.

\section{Author details}

'Department of Oncology, University Hospital Centre (KBC Zagreb), University of Zagreb School of Medicine, Zagreb, Croatia. ${ }^{2}$ Department of Clinical Immunology and Rheumatology, University Hospital Centre (KBC Zagreb), University of Zagreb School of Medicine, Zagreb, Croatia. ${ }^{3}$ Department of Diagnostic and Interventional Radiology, University Hospital Centre (KBC Zagreb), University of Zagreb School of Medicine, Zagreb, Croatia. ${ }^{4}$ Department of Pathology and Cytology, University Hospital Centre (KBC Zagreb), University of Zagreb School of Medicine, Zagreb, Croatia.

\section{Authors' contributions}

DK, BA and MM carried out the study design and writing. MS and NC participated in the data collection and interpretation and drafted the manuscript. RSP, KZ and SD participated in the design of the study and the figure design. SP participated in the literature search and helped to draft the manuscript. All authors read and approved the final manuscript.

\section{Competing interests}

Each coauthor certifies that he ore she has no commercial association that might pose a conflict of interest in connection with the submitted article.

Received: 8 July 2011 Accepted: 17 November 2011

Published: 17 November 2011

\section{References}

1. Diepgen TL, Mahler V: The epidemiology of skin cancer. Br J Dermatol 2002, 146:1-6.

2. Kounin GK, Romansky KV, Traykov LD, Shotekov PM, Stoilova DZ: Primary spinal melanoma with bilateral papilledema. Clin Neurol Neurosurg 2005, 107:525-527.

3. Naing A, Messina JL, Vrionis FR, Daud Al: Uncommon manifestations of common malignancies: case 3. Malignant melanoma arising from a spinal nerve root. J Clin Oncol 2004, 22:3194-3195.

4. Brat DJ, Giannini C, Scheithauer BW, Burger PC: Primary melanocytic neoplasms of the central nervous system. Am J Surg Pathol 1999, 23:745-754.

5. Hayward RD: Malignant melanoma and the central nervous system. J Neurol Neurosurg Psychiatry 1976, 39:526-530

6. Chapman PB, Einhorn LH, Meyers ML, Saxman S, Destro AN, Panageas KS, Begg CB, Agarwala SS, Schuchter LM, Ernstoff MS, Houghton AN, Kirkwood JM: Phase III Multicenter Randomized Trial of the Dartmouth Regimen Versus Dacarbazine in Patients With Metastatic Melanoma. J Clin Oncol 1999, 17:2745-2751.

7. Yamasaki T, Kikuchi H, Yamaschita J, Asato R, Fujita M: Primary spinal intramedullary malignant melanoma: case report. Neurosurgery 1989, 25:117-121.

8. Farrokh D, Fransen P, Faverly D: MR findings of a primary intramedullary malignant melanoma: case report and literature review. Am J Neuroradiol 2001, 22:1864-1866.

9. Larson TC, Houser OW, Onofrio BM, Peipgras DG: Primary spinal melanoma. J Neurosurg 1987, 66:47-49.

10. Isiklar I, Leeds NE, Fuller GN, Kumar AJ: Intracranial metastatic melanoma: correlation between MR imaging characteristics and melanin content. Am J Roentgenol 1995, 165:1503-1512.
11. Woodruff WW, Djang WT, McLendon RE, Heinz ER, Voorhees DR: Intracerebral malignant melanoma: high-field-strength MR imaging. Radiology 1987, 165:209-213.

12. Fon GT, Wong WS, Gold RH, Kaiser LR: Skeletal metastases of melanoma: radiographic, scintigraphic, and clinical review. Am J Roentgenol 1981, 137:103-108.

13. Edelstyn GA, Gillespie PJ, Grebell ES: The radiologic demonstration of osseous metastases: experimental observations. Clin Radiol 1967, 18:158-164.

14. Patten RM, Shuman WP, Teefey S: Metastases from malignant melanoma to the axial skeleton: a CT study of frequency and appearance. Am J Roentgenol 1990, 155:109-112.

15. Finger PT, Kurli M, Wesley P, Tena L, Kerr KR, Pavlick A: Whole body PET/CT imaging for detection of metastatic choroidal melanoma. $\mathrm{Br} J$ Ophthalmol 2004, 88:1095-1097.

16. Bhatia S, Tykodi SS, Thompson JA: Treatment of metastatic melanoma: an overview. Oncology 2009, 23:488-496.

17. Rate WR, Solin $L$, Turrisi AT: Palliative radiotherapy for metastatic malignant melanoma: brain metastases, bone metastases, and spinal cord compression. Int J Radiot Oncol Biol Phys 1988, 15:859-864.

18. Herbert SH, Solin Lj, Rate WR, Schultz DJ, Hanks GE: The effect of palliative radiation therapy on epidural compression due to metastatic malignant melanoma. Cancer 1991, 67:2472-2476.

19. Cooper JS: The evolution of the role of radiation therapy in the management of mucocutaneous malignant melanoma. Hematol Oncol Clin North Am 1998, 12:849-862.

20. Geara FB, Ang KK: Radiation therapy for malignant melanoma. Surg Clin North Am 1996, 76:1383-1398.

21. Hamilton AJ, Lulu BA, Fosmire H, Stea B, Cassady JR: Preliminary clinical experience with linear accelerator-based spinal stereotactic radiosurgery. Neurosurgery 1995, 36:311-319.

22. Gerszten PC: The role of minimally invasive techniques in the management of spine tumors: percutaneous bone cement augmentation, radiosurgery, and microendoscopic approaches. Orthop Clin North Am 2007, 38:441-450.

23. Gerszten PC, Ozhasoglu C, Burton SA, Vogel WJ, Atkins BA, Kalnicki S, Welch WC: CyberKnife frameless stereotactic radiosurgery for spinal lesions: clinical experience in 125 cases. Neurosurgery 2004, 55:89-99.

24. Falkson Cl, Ibrahim J, Kirkwood JM, Coates AS, Atkins MB, Blum RH: Phase III trial of dacarbazine versus dacarbazine with interferon alpha- $2 \mathrm{~b}$ versus dacarbazine with tamoxifen versus dacarbazine with interferon $a l p h a-2 b$ and tamoxifen in patients with metastatic malignant melanoma: an Eastern Cooperative Oncology Group study. J Clin Oncol 1998, 16:1743-1751.

25. Demchak PA, Mier JW, Robert NJ, O'Brien K, Gould JA, Atkins MB: Interleukin-2 and high-dose cisplatin in patients with metastatic melanoma: a pilot study. J Clin Oncol 1991, 9:1821-1830.

26. Flaherty LE, Robinson W, Redman BG, Gonzalez R, Martino S, Kraut M, Valdivieso M, Rudolph AR: A phase II study of dacarbazine and cisplatin in combination with outpatient administered interleukin-2 in metastatic malignant melanoma. Cancer 1993, 71:3520-3525.

27. Atkins MB, O'Boyle KR, Sosman JA, Weiss GR, Margolin KA, Ernest ML, Kappler K, Mier JW, Sparano JA, Fisher Rl: Multiinstitutional phase II trial of intensive combination chemoimmunotherapy for metastatic melanoma. J Clin Oncol 1994, 12:1553-1560.

28. Rosenberg SA, Yang JC, Schwartzentruber DJ, Hwu P, Marincola FM Topalian SL, Seipp CA, Einhorn JH, White DE, Steinberg SM: Prospective randomized trial of the treatment of patients with metastatic melanoma using chemotherapy with cisplatin, dacarbazine, and tamoxifen alone or in combination with interleukin-2 and interferon alfa-2b. $J$ Clin Oncol 1999, 17:968-975.

29. Huncharek M, Caubet JF, McGarry R: Single-agent DTIC versus combination chemotherapy with or without immunotherapy in metastatic melanoma: a meta-analysis of 3273 patients from 20 randomized trials. Melanoma Res 2001, 11:75-81.

30. Wöll E, Bedikian A, Legha SS: Uveal melanoma: natural history and treatment options for metastatic disease. Melanoma Res 1999, 9:575-581

31. O'Day SJ, Kim CJ, Reintgen DS: Metastatic Melanoma: Chemotherapy to Biochemotherapy. Cancer Control 2002, 9:31-38.

32. O'Day SJ, Atkins MB, Boasberg P, Wang HJ, Thompson JA, Anderson CM Gonzalez R, Lutzky J, Amatruda T, Hersh EM, Weber JS: Phase II multicenter 
trial of maintenance biotherapy after induction concurrent Biochemotherapy for patients with metastatic melanoma. J Clin Oncol 2009, 27:6207-6212.

33. Phan GQ, Yang JC, Sherry RM, Hwu P, Topalian SL, Schwartzentruber DJ, Restifo NP, Haworth LR, Seipp CA, Freezer LJ, Morton KE, Mavroukakis SA, Duray PH, Steinberg SM, Allison JP, Davis TA, Rosenberg SA: Cancer regression and autoimmunity induced by cytotoxic $\mathrm{T}$ lymphocyteassociated antigen 4 blockade in patients with metastatic melanoma. Proc Natl Acad Sci USA 2003, 100:8372-8377.

34. Robert C, Thomas L, Bondarenko I, O'Day S, MD JW, Garbe C, Lebbe C, Baurain JF, Testori A, Grob JJ, Davidson N, Richards J, Maio M, Hauschild A, Miller WH Jr, Gascon P, Lotem M, Harmankaya K, Ibrahim R, Francis S, Chen TT, Humphrey R, Hoos A, Wolchok JD: Ipilimumab plus dacarbazine for previously untreated metastatic melanoma. N Engl J Med 2011, 364:2517-2526.

35. Hodi FS, O'Day SJ, McDermott DF, Weber RW, Sosman JA, Haanen JB, Gonzalez R, Robert C, Schadendorf D, Hassel JC, Akerley W, van den Eertwegh AJ, Lutzky J, Lorigan P, Vaubel JM, Linette GP, Hogg D, Ottensmeier CH, Lebbé C, Peschel C, Quirt I, Clark JI, Wolchok JD, Weber JS, Tian J, Yellin MJ, Nichol GM, Hoos A, Urba WJ: Improved survival with ipilimumab in patients with metastatic melanoma. N Engl J Med 2010 363:711-23.

36. Chapman PB, Hauschild A, Robert C, Haanen JB, Ascierto P, Larkin J, Dummer R, Garbe C, Testori A, Maio M, Hogg D, Lorigan P, Lebbe C, Jouary T, Schadendorf D, Ribas A, O'Day SJ, Sosman JA, Kirkwood JM, Eggermont AM, Dreno B, Nolop K, Li J, Nelson B, Hou J, Lee RJ, Flaherty KT, McArthur GA, BRIM-3 Study Group: Improved survival with vemurafenib in melanoma with BRAF V600E mutation. N Engl J Med 2011, 364:2507-2516.

37. Machet L, Perrinaud A, Giraudeau B: Routine ultrasonography in melanoma follow-up? The Lancet Oncology 2005, 6:2.

38. DiFronzo LA, Wanek LA, Morton DL: Earlier diagnosis of second primary melanoma confirms the benefits of patient education and routine postoperative follow-up. Cancer 2001, 91:1520-1524.

doi:10.1186/1477-7819-9-150

Cite this article as: Katalinic et al:: Low back pain as the presenting sign in a patient with primary extradural melanoma of the thoracic spine - A metastatic disease 17 Years after complete surgical resection. World Journal of Surgical Oncology 2011 9:150.

\section{Submit your next manuscript to BioMed Central and take full advantage of:}

- Convenient online submission

- Thorough peer review

- No space constraints or color figure charges

- Immediate publication on acceptance

- Inclusion in PubMed, CAS, Scopus and Google Scholar

- Research which is freely available for redistribution

Submit your manuscript at www.biomedcentral.com/submit 